\title{
Biochemical and hematological reference intervals for Krefft's turtles Emydura macquarii krefftii from the Burnett River Catchment, Australia
}

\author{
Mark Flint ${ }^{1,2, *}$, Duncan J. Limpus ${ }^{3}$, Colin J. Limpus ${ }^{2,3}$, Janet C. Patterson-Kane ${ }^{2,4}$, \\ Jennifer A. Eales ${ }^{2}$, Paul C. Mills ${ }^{2}$ \\ ${ }^{1}$ Aquatic Animal Health, College of Veterinary Medicine, University of Florida, Gainesville, Florida 32608, USA \\ ${ }^{2}$ Veterinary-Marine Animal Research, Teaching and Investigation (Vet-MARTI) unit, School of Veterinary Science, \\ The University of Queensland, St. Lucia, Queensland 4072, Australia \\ ${ }^{3}$ Department of Environment and Resource Management, PO Box 2454, City, Queensland 4001, Australia \\ ${ }^{4}$ Faculty of Veterinary Medicine, The University of Glasgow, Bearsden Road, Glasgow G61 1QH, UK
}

\begin{abstract}
Biochemical and hematological reference intervals have not previously been reported for Emydura macquarii krefftii. In 2009, 56 E. m. krefftii were captured by hand from the Burnett Catchment, clinically assessed to determine health status and blood sampled. Reference intervals were calculated from the 35 clinically healthy turtles using techniques established in other chelonid species. Aberrant blood results were identified from the 21 clinically unhealthy turtles. Low numbers of observed cases of creatine kinase, glucose, magnesium, phosphorus and uric acid outside of the blood biochemistry reference interval were recorded, as were high numbers of observed cases of estimated eosinophils, thrombocytes and total leukocyte counts outside of the hematological reference interval. Lesions of the shell and plastron (shell rot) were observed in $38 \%(21 / 56)$ of the examined healthy and unhealthy turtles. Microbiological assessment of a subsample $(\mathrm{n}=7)$ of these lesions grew Aeromonas veronii 100\% (7/7), Aeromonas hydrophila 29\% (2/7) and Acinetobacter baumannii $14 \%(1 / 7)$. Of the examined turtles, $13 \%(7 / 56)$ had evidence of opacity of the lens or anterior chamber of the eye and $70 \%$ (39/56) had erythema of the neck, axillary and inguinal soft tissues. Not all observed cases of erythema were associated with clinical ill-health. The anomalous blood results and clinical findings identified in this study suggest disease processes which may have resulted from causative agents in the surrounding environment.
\end{abstract}

KEY WORDS: Aeromonas $\cdot$ Blood biochemistry $\cdot$ Disease $\cdot$ Environmental factor $\cdot$ Hematology · Emydura macquarii krefftii $\cdot$ Shell rot

\section{INTRODUCTION}

Of the 38 species including subspecies of freshwater turtles in Australia, there are currently 15 described species, 4 subspecies and one undescribed species recognised to occur in Queensland (Georges \& Thomson 2010). Little is known about the diseases influencing the survivorship of these species or the effects environment is having on their health and well-being. Few reports describe the diseases or primary known man-made threats to these species (Limpus et al. 2002). Disease has only been investigated during mass mortality events (Tucker et al. 2002, Flint 2009), preventing the understanding of background pathologies that is gained when carcasses of animals not undergoing an extraordinary disease event are examined. 
Emydura macquarii krefftii (Grey 1871) is an Australian native turtle found in Queensland east of the Great Dividing Range from the Cape York Peninsula southward to Cape Charlotte Bay. The species exhibits sexual dimorphism, with females being larger than males. Mating takes place in autumn, late winter and spring, and nesting from September to January. The eggs are white, hard-shelled, and ellipsoidal and normal clutch size may vary from 4 to 18 eggs. Longevity has not been determined (Cann 1978, Legler \& Cann 1980, Georges 1983).

This study has been initiated in response to a perceived increase in the numbers of free-ranging freshwater turtles in poor body condition in the Burnett River and associated deaths of some of these turtles. Intermittent studies of Emydura macquarii krefftii river turtle populations in the Burnett Catchment in Queensland have been undertaken since 1994 (Tucker et al. 2000, Limpus et al. 2002, Hamann et al. 2007, Hamann et al. 2008). Until recently, no evidence of breeding rate loss has been observed (Queensland Government Department of Environment and Resource Management [DERM] Queensland Freshwater Turtle Conservation Project database unpubl. data). However, since late 2007, E. m. krefftii sampled in this catchment, as part of an ongoing DERM project, have been anecdotally noted to be entering and sustaining a state of poor condition beyond what is expected of natural seasonal or breeding cycles. In many cases, animals previously recorded in advanced vitellogenesis have reabsorbed mature follicles throughout the breeding season while losing body condition. In several isolated cases, death has occurred (DERM unpubl. data).

Causes for these recent events are believed to be of environmental origin but, in the absence of baseline data such as blood biochemical and hematological reference intervals and reported 'background' pathogens, determining the causative agent is speculative.

The aims of this study were to develop reference intervals for Emydura macquarii krefftii in the Burnett Catchment, determine the clinical pathology in diseased animals, and determine the gross and microscopic pathology of identified diseases.

\section{MATERIALS AND METHODS}

Study site and animal selection. Ned Churchward Weir (or Walla Weir), located approximately $5 \mathrm{~km}$ north-east of Wallaville and $35 \mathrm{~km}$ south-west of Bundaberg on the Burnett River within the Burnett Catchment, Queensland, Australia; $25.05^{\circ} \mathrm{S}, 152.09^{\circ} \mathrm{E}$, is a man-made structure creating a flow break for the Burnett River and resulting in the formation of multiple slow moving pools downstream of the weir. At the time of the study, these pools ranged in depth from 1 to $3 \mathrm{~m}$, with a rock and sand substrate bordered by medium density riparian vegetation including predominantly Callistemon spp. overhang. These pools periodically flood during water release. Resident populations of Emydura macquarii krefftii are found in these pools year round but are capable of exiting the pools and waterway if they want to.

One night in January and 2 nights in May, 2009, a range of healthy and unhealthy Emydura macquarii krefftii ( $\mathrm{n}=56$ ) were collected on snorkel by convenience sampling (Dohoo et al. 2003). In brief, a diver systematically swam through the riverine pools at night using battery operated high-powered underwater lights to illuminate the pool beds. By swimming up and down the pool at the width of the light beam, complete coverage of the bed was achieved and every turtle encountered was captured. When a turtle was spotted, it was collected by hand and placed in a netted dive bag for subsequent examination. This selection method reduced the likelihood of a biased sample.

Gender, maturity and breeding status. Gender, maturity and breeding status were determined using external morphological measurements, palpation for the presence of oviducal eggs, or gonad examination by ultrasound or laparoscopy (Limpus et al. 2002, Limpus \& Limpus 2003, Hamann et al. 2008).

Turtle health. Each turtle was clinically assessed and a blood sample collected from the external (lateral) jugular.

Clinical assessment. Turtles having a notable reduction in muscle mass around the limbs, neck and eye sockets were defined as being in 'poor condition' in accordance with previously described methods used in other turtle species (Flint et al. 2009a, 2010). In addition, specific for freshwater turtles, a poor body condition was defined as one whereby a breeding adult was not in breeding condition (reabsorbed follicles or small gonads). External conditions (e.g. shell rot) did not contribute to determining body condition, but did contribute to the assigned health status. Turtles having a minor loss of muscle mass and/or fat around the limbs, neck and eye sockets were considered to be in 'average' condition. Otherwise, turtles were classified as having a 'good body condition'.

Turtles in good body condition, displaying no clinically apparent abnormalities (Herbst \& Jacobson 2003), neurological deficits (Chrisman et al. 1997) or lesions of the carapace or plastron (Flint 2009) were classified as 'clinically healthy'. Animals of 'average body condition' were classed as healthy or poor depending on lesions and other recorded abnormalities. Turtles in poor body condition and/or exhibiting clinical abnormalities were classified as 'clinically unhealthy' and examined in detail to determine cause of disease. 
For each animal, the number of lesions on the carapace and plastron were counted and trauma noted (Fig. 1).

Blood collection and preparation. Blood samples were collected via the external jugular, prepared and examined using previously described techniques (Owens \& Ruiz 1980, Rogers \& Booth 2004, Flint et al. $2009 b$ ), with minor modifications. In brief, blood samples (3-5 ml) were collected from turtles using a $22 \mathrm{G}$ $38 \mathrm{~mm}$ needle attached to a $5 \mathrm{ml}$ syringe. Voided samples were transferred to a heparinized evacuated tube, and placed in coolers $\left(4^{\circ} \mathrm{C}\right)$ until centrifuging, which occurred within $6 \mathrm{~h}$ of collection. A blood smear was immediately made from fresh blood collected from the syringe and air dried. Samples were centrifuged (Hettich EBA-20) at $400 \times g$ for $3 \mathrm{~min}$ where required. Once separated, up to $3 \mathrm{ml}$ of the plasma was frozen at $-20^{\circ} \mathrm{C}$ for not longer than $2 \mathrm{wk}$ before analysis.

Plasma biochemistry. Plasma samples were thawed to room temperature then run on a calibrated autoanalyzer (Olympus AU400). The following plasma variables were measured: albumin, alkaline phosphatase (ALP), aspartate transaminase (AST), calcium, chloride, creatine kinase $(\mathrm{CK})$, creatinine, globulins, lactic dehydrogenase (LDH), magnesium, phosphorus, potassium, protein, sodium, urea and uric acid.

Hematology. Blood smears were stained (WrightGiemsa), and sealed using resin and a cover slip. A representative monolayer was selected for a differential white cell count (WCC); 200 white cells (leukocytes) were counted using a binocular light microscope and a $100 \times$ oil emersion lens. Cells were classified as thrombocytes, lymphocytes, heterophils, eosinophils, basophils or monocytes (Work et al. 1998). Estimated total white cell counts (TWCC) were determined by previously described methods (Conelly 1990).

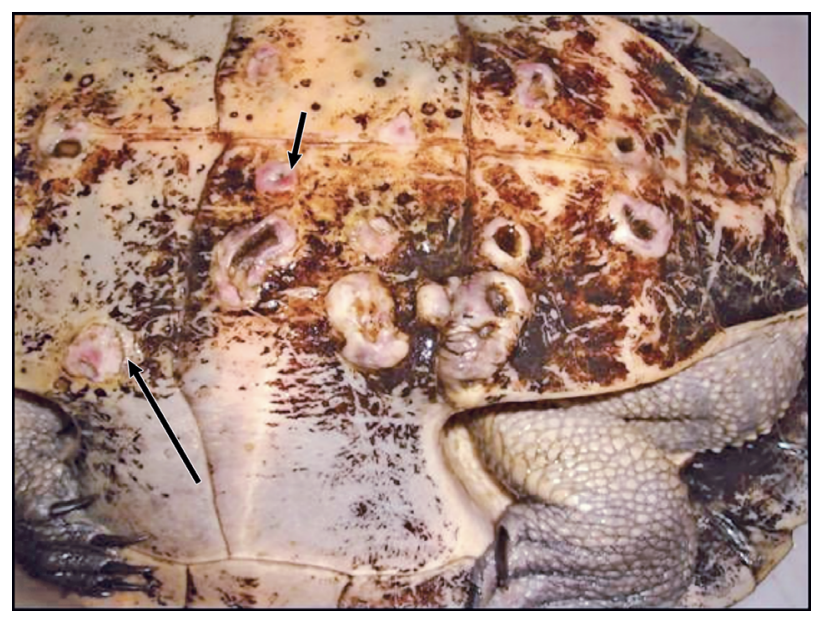

Fig. 1. Emydura macquarii krefftii. Common lesions of the plastron (Tag No. 42948, Burnett Catchment). Inflammation and suspected osteomyelitic changes are indicated by arrows
Microbiology. Sterile swabs of active shell rot lesions were obtained (Trott et al. 2003) for a subsample (7/56) of the Emydura macquarii krefftii to culture bacteria at the Microbiology Department in the School of Veterinary Science at The University of Queensland. Swabs were replaced in transport media and chilled at $4^{\circ} \mathrm{C}$ for a maximum of $72 \mathrm{~h}$ prior to submission. For samples producing Aeromonas spp. bacterium, sensitivity to a standard panel of 11 antimicrobials was determined.

Statistical analyses. Estimating reference intervals. Using previously described methods, data was tested to determine if subgroups (gender and maturity) could be grouped for calculation of a single reference interval (Flint et al. 2009a); $95 \%$ reference intervals and associated $90 \%$ confidence intervals for the limits of each interval were estimated using RefVal 4.11 software program (Solberg 2006) as per previously described methods (Flint et al. 2009a, 2010).

Describing biochemical and hematological variables in clinically unhealthy turtles. Proportions of clinically unhealthy turtles with results outside the reference interval were calculated for each biochemical and hematological variable. Exact $95 \%$ confidence intervals were calculated for each proportion using Stata version 10 (StataCorp). Proportions of turtles with disease syndromes and bacterial infections identified by clinical examination were calculated for gender and age.

\section{RESULTS AND DISCUSSION}

\section{Population structure and clinical health}

Of the 56 Emydura macquarii krefftii examined in this investigation, $63 \%(35 / 56)$ were classed as clinically healthy. Of these, $51 \%$ (18/35) were male, $29 \%$ (10/35) female and $20 \%$ (7/35) unknown; $14 \%(5 / 35)$ were small immature turtles, $83 \%$ (29/35) were mature turtles and $3 \%(1 / 35)$ were not determined. No large immature turtles were included in this study (Table 1).

\section{Determination of baseline blood biochemistry and hematology}

Exploratory analyses of the inter-quartile range widths of the subgroups of clinically healthy Emydura macquarii krefftii confirmed subgroups could be combined to produce biochemical and hematological reference intervals without the need for subdivision. Previous use of RefVal as a reference interval calculator in data on free-ranging marine turtles has shown this technique to produce robust intervals using as few 
Table 1. Emydura macquarii krefftii. Health status of turtles sampled at Ned Churchward, Australia, Weir in May 2009, showing mean $( \pm \mathrm{SD})$ weight and straight carapace length (SCL) of healthy and unhealthy animals

\begin{tabular}{|llccc|}
\hline Sex & $\begin{array}{l}\text { Health } \\
\text { status }\end{array}$ & $\begin{array}{c}\text { No. of } \\
\text { turtles }\end{array}$ & $\begin{array}{c}\text { Weight } \\
(\mathrm{kg})\end{array}$ & SCL $(\mathrm{cm})$ \\
\hline Male & Healthy & 18 & $1.42( \pm 0.4)$ & $23.21( \pm 1.5)$ \\
Female & Unhealthy & 9 & $1.36( \pm 0.3)$ & $23.33( \pm 1.6)$ \\
& Healthy & 10 & $1.75( \pm 0.3)$ & $24.71( \pm 1.3)$ \\
Undetermined & Unhealthy & 11 & $1.78( \pm 0.5)$ & $24.58( \pm 2.4)$ \\
& Healthy & 7 & $0.65( \pm 0.7)$ & $16.23( \pm 6.1)$ \\
& Unhealthy & 1 & 0.56 & 16.67 \\
\hline
\end{tabular}

as 20 animals if variance among values is low (Horn et al. 1998, Flint et al. 2009a). Robust baseline health data was derived using blood values from these clinically healthy animals for biochemistry (Table 2) and hematology (Table 3).
The proportion of clinically unhealthy turtles across the gender and maturity classes was greater than would be expected in the wild population for this region (DERM unpubl. data), indicating that a disease syndrome and/or environmental factor may have been affecting the examined turtles at the population level.

\section{Blood biochemical and hematological anomalies in clinically unhealthy turtles}

Amongst the unhealthy turtles, only a low proportion of animals had blood biochemistry values outside the presented reference interval but a high proportion of animals had hematologic values outside of the presented reference interval. Anomalous values in unhealthy animals were: decreased glucose (3/20 turtles or $15 \%$; $95 \%$ CI: 3-38\%), phosphorous (2/20, $10 \%$; $95 \%$ CI: $1-32 \%)$, estimated thrombocyte counts

\section{Clinically unhealthy turtles}

In this study, 38\% (21/56) of Emydura macquarii krefftii examined were classed as clinically unhealthy. Of these, $43 \%$ (9/21) were male, $52 \%$ $(11 / 21)$ female and $5 \%(1 / 21)$ unknown; $10 \%$ (2/21) were small immature turtles, $5 \%(1 / 21)$ large immature turtles, $76 \%(16 / 21)$ were adults, and $10 \%(2 / 21)$ were not determined (Table 1).
Table 3. Emydura macquarii krefftii Hematology for healthy turtles sampled downstream of Ned Churchward Weir, Australia, May 2009. Blood counts $\left(\times 10^{9} \mathrm{l}^{-1}\right)$ are estimates

\begin{tabular}{|lcccc|}
\hline Variable & $\mathrm{n}$ & $\begin{array}{c}\text { Mean } \\
( \pm \mathrm{SD})\end{array}$ & $\begin{array}{c}\text { 95\% reference interval }(90 \% \mathrm{CI}) \\
\text { Lower limit }\end{array}$ & Upper limit \\
\hline Thrombocytes & 20 & $8.0( \pm 5.1)$ & $1.1(0.6,1.7)$ & $22.0(15.4,25.9)$ \\
Lymphocytes & 20 & $5.1( \pm 4.2)$ & $0.1(0.0,0.2)$ & $15.3(12.8,17.2)$ \\
Heterophils & 20 & $17.1( \pm 7.9)$ & $6.6(5.6,7.6)$ & $38.9(30.6,44.9)$ \\
Eosinophils & 20 & $4.4( \pm 0.6)$ & $0.2(0.2,0.2)$ & $1.9(1.3,2.5)$ \\
Monocytes & 20 & $2.9( \pm 2.1)$ & $0.3(0.1,0.5)$ & $8.7(6.8,9.7)$ \\
Basophils & 20 & $0.0( \pm 0.0)$ & $0.0(0.0,0.0)$ & $0.0(0.0,0.0)$ \\
Total white cell count & 20 & $3.4( \pm 11.1)$ & $14.7(11.9,17.0)$ & $62.7(54.1,68.1)$ \\
\hline
\end{tabular}

Table 2. Emydura macquarii krefftii. Blood biochemistry for healthy turtles sampled downstream of Ned Churchward Weir, Australia, May 2009. ALP: alkaline phosphatase; AST: asparate transaminase; LDH: lactic dehydrogenase

\begin{tabular}{|c|c|c|c|c|c|}
\hline \multirow[t]{2}{*}{ Variable } & \multirow[t]{2}{*}{ SI } & \multirow[t]{2}{*}{$\mathrm{n}$} & \multirow[t]{2}{*}{ Mean $( \pm \mathrm{SD})$} & \multicolumn{2}{|c|}{$95 \%$ reference interval (90\% CI) } \\
\hline & & & & Lower limit & Upper limit \\
\hline Albumin & $\mathrm{g} \mathrm{l}^{-1}$ & 35 & $11.7(3.4)$ & $5.7(5.0,6.7)$ & $19.1(17.4,21.2)$ \\
\hline ALP & $\mathrm{U} \mathrm{l}^{-1}$ & 34 & $41.1(20.4)$ & $21.6(20.0,23.6)$ & $74.3(58.8,86.1)$ \\
\hline AST & $\mathrm{U} \mathrm{l}^{-1}$ & 35 & $487.8(487.8)$ & $69.3(47.7,101.1)$ & $1827.8(1103.7,2319.2)$ \\
\hline Calcium & $\mathrm{mmol} \mathrm{l}^{-1}$ & 35 & $2.3(0.6)$ & $1.6(1.5,1.7)$ & $3.8(3.5,4.2)$ \\
\hline Chloride & $\mathrm{mmol} \mathrm{l}^{-1}$ & 35 & $99.8(4.3)$ & $91.5(\mathrm{n} / \mathrm{a})$ & $107.3(\mathrm{n} / \mathrm{a})$ \\
\hline Creatinine & umol l-1 & 34 & $21.2(24.9)$ & $10.6(9.7,11.6)$ & $24.3(22.4,25.8)$ \\
\hline Creatine kinase & $\mathrm{U} \mathrm{l}^{-1}$ & 35 & $19873.4(26654.6)$ & $306.9(78.6,863.8)$ & $93429.8(45677.1,122935.1)$ \\
\hline Globulin & $g \mathrm{l}^{-1}$ & 35 & $28.0(6.7)$ & $15.3(12.8,18.1)$ & $43.0(38.4,46.8)$ \\
\hline Glucose & mmol l-1 & 35 & $2.6(1.8)$ & $0.6(0.0,0.8)$ & $7.2(6.1,7.8)$ \\
\hline LDH & $\mathrm{U} \mathrm{l}^{-1}$ & 35 & $3530.0(4296.3)$ & $773.2(615.3,989.4)$ & $15526.0(7411.8,20264.3)$ \\
\hline Magnesium & $\mathrm{mmol} \mathrm{l}^{-1}$ & 35 & $1.1(0.2)$ & $0.8(0.8,0.8)$ & $1.5(1.4,1.6)$ \\
\hline Phosphorous & mmol l $1^{-1}$ & 35 & $0.9(0.2)$ & $0.6(0.5,0.6)$ & $1.5(1.3,1.5)$ \\
\hline Potassium & $\mathrm{mmol} \mathrm{l}^{-1}$ & 35 & $4.0(1.0)$ & $2.8(2.6,2.9)$ & $6.5(5.5,7.2)$ \\
\hline Protein & $\mathrm{g} \mathrm{l}^{-1}$ & 35 & $40.0(9.2)$ & $20.4(17.0,24.9)$ & $58.2(54.2,62.8)$ \\
\hline Sodium & mmol $\mathrm{l}^{-1}$ & 35 & $134.4(3.9)$ & $125.9(\mathrm{n} / \mathrm{a})$ & $143.2(\mathrm{n} / \mathrm{a})$ \\
\hline Urea & $\mathrm{mmol} \mathrm{l}^{-1}$ & 35 & $1.5(0.9)$ & $0.6(0.6,0.6)$ & $3.9(2.8,4.7)$ \\
\hline Uric acid & umol l ${ }^{-1}$ & 35 & $132.0(56.6)$ & $59.8(53.5,67.7)$ & $280.2(231.1,321.6)$ \\
\hline
\end{tabular}


(1/15, $7 \%$; $95 \%$ CI: 0-32\%) and estimated eosinophils counts (11/15, 73\%; 95\% CI: 45-92\%); and increased uric acid $(3 / 20,15 \%$; $95 \%$ CI: 3-38\%), magnesium $(1 / 20,5 \%$; $95 \%$ CI: $0-25 \%)$, phosphorus $(1 / 20,5 \%$; $95 \%$ CI: $0-25 \%)$, creatine kinase $(2 / 20,10 \%$; $95 \% \mathrm{CI}$ : $1-32 \%)$, estimated thrombocytes count (7/15, $47 \%$; $95 \%$ CI: $21-73 \%$ ), estimated lymphocyte counts (4/15, $27 \%$; 95\% CI: 8-55\%), estimated heterophil counts $(2 / 15,13 \% ; 95 \%$ CI: $2-40 \%)$ and estimated TWCC (9/15, $60 \%$; $95 \%$ CI: 32-84\%).

The noted anomalies in blood parameters suggested that renal (for e.g. high uric acid and altered phosphorus), hepatic (for e.g. hypoglycemic), and catabolic (for e.g. high creatine kinase levels) pathological processes may have been present within the studied population that was associated with potential inflammatory or infectious processes (high estimated TWCC) (Campbell 2006). Potential causes could include systemic bacterial infection/septicemia, or natural or introduced toxins, but these speculations require more rigorous testing before links between the observed clinical pathology and cause can be upheld (Campbell 2006).

\section{Clinical abnormalities in unhealthy turtles}

Based on physical examination, 3 types of abnormality were frequently observed in unhealthy turtles: shell rot, opacity of the lens or anterior chamber of the eye, and soft tissue erythema of the neck, axilla and inguinal regions. These abnormalities may have had a common potentiating factor of an environmental contaminant, irritant or infection.

Shell rot, that is, ulcerations of the shell that may be initiated by disease, toxicity, nutritional deficiency or trauma but are usually colonised by bacteria or fungus (Boyer 2006), occurred in $38 \%$ (21/56) of the examined Emydura macquarii krefftii. They were active in almost all cases, exceeding figures reported for healthy sites of the Burnett Catchment (Limpus et al. 2006) but consistent with sites of suspected disease outbreaks (Tucker et al. 2002). Despite the presence of shell lesions, $24 \%(5 / 21)$ of these animals with shell rot were classed as otherwise healthy, irrespective of lesion severity. Overall, lesions ranged in size from 10 to $25 \mathrm{~mm}$ in diameter. Those on the carapace appeared to be superficial with associated necrosis. Those on the plastron were predominantly superficial, but several involved the underlying bone with the margin of the lesion inflamed (Fig. 1). In these cases, a tentative diagnosis of osteomyelitis was made. The cause of these outbreaks was not identified.

Culturing swabs of shell rot lesions from the carapace and/or plastron on 7 Emydura macquarii krefftii resulted in predominant heavy mixed growth of
Aeromonas veronii bio sobria ( $\mathrm{n}=7$ ). Aeromonas hydrophila ( $\mathrm{n}=2$ ) and Acinetobacter baumannii $(\mathrm{n}=1)$ were also noted. These pathogens are ubiquitous in the environment but have pathogenic consequences in immunocompromised or septicemic patients (Wolff et al. 1980, Chen et al. 2005, Roberts et al. 2006) including fish and aquatic reptiles. Environmental components such as water temperature and flow, contaminants and nutrient levels are implicated in the increased pathogenicity of these bacteria. A. veronii and $A$. baumannii have the capacity to transfer between animals, environment and humans, but the latter is a sapronotic (environmental) pathogen. A. hydrophila has been identified as a significant pathogen in mass mortalities of chelonians (Jacobson 2007). Antibiotic sensitivity testing revealed that the Aeromonas spp. were susceptible to tetracycline, doxycycline, trimethoprim sulfadiazine (TMS), enrofloxacin, gentamicin, cephalexin, ciprofloxacin and ceftazadime. The turtles examined in this study showed evidence of an active inflammatory response (elevated TWCC) which is consistent with, but not specific for, presence of an infectious (pathogenic) process.

Unilateral or bilateral opacity of the lens or anterior chamber (not confirmed histologically) occurred in $13 \%(7 / 56)$ of the examined Emydura macquarii krefftii. Aeromonas hydrophila has previously been implicated in eye conditions, such as iridocyclitis in American alligators, and may be a possible cause of the noted eye opacity (Jacobson 2007).

Erythema of the soft tissues, particularly at the junction of the plastron and epidermis, was recorded in $70 \%(39 / 56)$ of the examined Emydura macquarii krefftii; $92 \%(36 / 39)$ of these cases were classed as mild (light pink discoloration noted in at least one of the neck, axillary or inguinal regions) and $8 \%$ (3/39) of cases were classed as moderate (pink to light red discoloration of more than one of the neck, axillary or inguinal regions). No cases were considered severe (red discoloration of the neck, axillary and inguinal regions), and it was difficult to discern grossly as to whether it was an infectious or inflammatory process. A contact dermatitis contracted from an environmental contamination (Boyer 2006) was the likely cause, but as for shell rot and eye opacity, bacteria such as Aeromonas spp. may have been a contributing factor.

Other clinical conditions noted in Emydura macquarii krefftii examined during this study were trauma-related, including resolved fractures of the carapace $(\mathrm{n}=3$ ) and subcutaneous foreign bodies ( $\mathrm{n}$ $=2$ ) and algal overgrowth on the carapace $(n=1)$. These were not considered to be extraordinary findings within the population and have been commonly reported for this catchment (Limpus et al. 2002, 2006). 
This investigation produced the first hematological and biochemical blood reference intervals for Krefft turtles in Australia, providing a useful tool in the diagnosis of disease in free-ranging freshwater turtles. Comparing the bloods of clinically unhealthy turtles to the reference interval suggested there were active disease processes affecting Krefft freshwater turtles, at least in this sampled section of the Burnett River Catchment. Confirmatory studies such as environmental assessment, further investigation of the speculated diagnoses and refinement of techniques are warranted.

Acknowledgements. This disease investigation for which these reference intervals were constructed was conducted by The University of Queensland's Veterinary-Marine Animal Research, Teaching and Investigation (Vet-MARTI; www. uq.edu.au/vetschool/index.html?page $=101785$ ) unit for the Department of Environment and Resource Management's Freshwater Turtle Conservation Project under Animal Ethics Approval (DERM 2009/10/07). Sample collection was assisted by DERM staff P. Evans and C. Johnson, and registered QTCP volunteer J. Gatley. Access to the study site is allowed by SunWater, and Associate Professor D. Trott provided constructive comments on the manuscript. All contributions are gratefully acknowledged.

\section{LITERATURE CITED}

Boyer TH (2006) Turtles, tortoises, and terrapins. In: Mader DR (ed) Reptile medicine and surgery, 2nd edn. Saunders Elsevier, St. Louis, MO, p 696-704

Campbell TW (2006) Clinical pathology of reptiles. In: Mader DR (ed) Reptile medicine and surgery, 2nd edn. Saunders Elsevier, St. Louis, MO, p 453-470.

Cann J (1978) Tortoises of Australia. Angus and Robertson, Sydney

Chen HP, Chen TL, Lai CH, Fung CP, Wong WW, Yu KW, Liu CY (2005) Predictors of mortality in Acinetobacter baumannii bacteremia. J Microbiol Immunol Infect 38:127-136

Chrisman CL, Walsh M, Meeks JC, Zurawka H, LaRock R, Herbst LH (1997) Neurological examination of sea turtles. J Am Vet Med Assoc 211:1043-1047

Conelly F (1990) Avian haematology and Gram staining. Basic tools in diagnosing the avian patient. In: Caged and aviary bird medicine - avian haematology. Association of Avian Veterinarians Australian Committee, Sydney, p 1-14

Dohoo I, Martin W, Stryhn H (2003) Sampling. In: Dohoo I, Martin W, Stryhn H (eds) Veterinary epidemiologic research. AVC, Charlottetown, p 27-53

Flint M (2009) Freshwater turtle disease investigation for the Burnett Catchment Central Queensland. Final report August 2009. Veterinary Marine Animal Research, Teaching and Investigation Unit, The University of Queensland, Brisbane

Flint M, Morton JM, Limpus CJ, Patterson-Kane JC, Murray PJ, Mills PC (2009a) Development and application of biochemical and haematological reference intervals to identify unhealthy green sea turtles (Chelonia mydas). Vet J 185:299-304

> Flint M, Patterson-Kane JC, Limpus CJ, Work TM, Blair D, Mills PC (2009b) Post mortem diagnostic investigation of disease in free-ranging marine turtle populations: a review of common pathological findings and protocols.
J Vet Diagn Invest 21:733-759

Flint M, Morton JM, Patterson-Kane JC, Limpus CJ, Mills PC (2010) Reference intervals for plasma biochemical and hematological measures in loggerhead sea turtles (Caretta caretta) from Moreton Bay, Australia. J Wildl Dis 46: 731-741

$>$ Georges A (1983) Reproduction of the Australian freshwater turtle Emydura krefftii (Chelonia: Chelidae). J Zool 201: $331-350$

Georges A, Thomson S (2010) Diversity of Australian freshwater turtles, with an annotated synonymy and key to species. Zootaxa 2496:1-37

Hamann M, Schauble CS, Limpus DJ, Emerick SP, Limpus CJ (2007) Management plan for the conservation of Elseya sp. [Burnett River] in the Burnett River Catchment. Queensland Environmental Protection Agency, Brisbane

Hamann M, Schauble CS, Emerick SP, Limpus DJ, Limpus CJ (2008) Freshwater turtle populations in the Burnett River. Mem Queensl Mus 52:221-232

Herbst LH, Jacobson ER (2003) Practical approaches for studying sea turtle health and disease. In: Lutz P, Musick JA, Wyneken J (eds) The biology of sea turtles, Vol II. CRC Press, Boca Raton, FL, p 385-410

Horn PS, Pesce AJ, Copeland BE (1998) A robust approach to reference interval estimation and evaluation. Clin Chem 44:622-631

Jacobson ER (2007) Bacterial diseases of reptiles. In: Jacobson ER (ed) Infectious diseases and pathology of reptiles: color atlas and text. CRC Press, Boca Raton, FL, p 461-526

Legler JM, Cann J (1980) A new genus and species of chelid turtle from Queensland, Australia. Natural History Museum of Los Angeles County, Los Angeles, CA

Limpus CJ, Limpus DJ (2003) The biology of the loggerhead turtle, Caretta caretta, in Western South Pacific Ocean foraging areas. In: Witherington B, Bolten A (eds) Biology and conservation of loggerhead turtles. Smithsonian Institution Press, Washington, DC, p 93-113

Limpus CJ, Limpus DJ, Hamann M (2002) Freshwater turtle populations in the area to be flooded by the Walla Weir, Burnett River, Queensland: baseline study. Mem Queensl Mus 48:155-168

Limpus DJ, Hodge WJ, Limpus CJ (2006) Impacts of dams and weirs on freshwater turtles: Fairbairn Dam, March 2006. Queensland Environmental Protection Agency, Brisbane

Owens DW, Ruiz GJ (1980) New methods of obtaining blood and cerebrospinal fluid from marine turtles. Herpetologica $36: 17-20$

Roberts MTM, Enoch DA, Harris KA, Karas JA (2006) Aeromonas veronii biovar sobria bacteraemia with septic arthritis confirmed by $16 \mathrm{~S}$ rDNA PCR in an immunocompetent adult. J Med Microbiol 55:241-243

$>$ Rogers KD, Booth DT (2004) A method of sampling blood from Australian freshwater turtles. Wildl Res 31:93-95

Solberg HE (2006) RefVal 4.11 user's guide. RefVal, Rykinn

Trott DJ, Moss SM, Townsend KM (2003) Veterinary microbiology practical manual - VETS3001. The University of Queensland, St Lucia

Tucker AD, Kelly WR, Limpus CJ, Priest TE, Guarino F (2002) Prevalence of ulcerative disease in free-ranging Krefft's turtle. Mem Queensl Mus 48:233-238

> Wolff RL, Wiseman SL, Kitchens CS (1980) Aeromonas hydrophila bacteremia in ambulatory immunocompromised hosts. Am J Med 68:238-242

Work TM, Raskin RE, Balazs GH, Whittaker SD (1998) Morphologic and cytochemical characteristics of blood cells from Hawaiian green turtles. Am J Vet Res 59: $1252-1257$

Submitted: August 30, 2010; Accepted: February 27, 2011

Proofs received from author(s): May 13, 2011 